\title{
TOXICOLOGIA FORENSE E SUA IMPORTÂNCIA NA SAÚDE PÚBLICA
}

\author{
Samantha Stanco de Jesus ${ }^{1}$ \\ Daniel Sachs Silva ${ }^{2}$
}

RESUMO: O presente trabalho tem como fito, discorrer sobre o tema da toxicologia forense como instrumento essencial à identificação de substâncias danosas aos organismos, visto que, muitas vezes, o uso inadequado de determinados reagentes químicos, podem causar danos irreparáveis; apresentando-se, portanto, como tema de alta relevância à saúde pública e a sociedade em geral. Nesse sentido, o papel do perito se apresenta como "sine qua non" para elucidação de crimes e infrações nos casos de envenenamento; superdosagem de drogas; alterações de substâncias, onde através de análise e coleta de material biológico, tal profissional angariará subsídios concretos a fim de obter provas conclusivas, corroboradas em seu laudo técnico. Nesta área de conhecimento, atuam profissionais de diversas formações e por isso é compreendida como multidisciplinar, por exemplo: toxicologia ocupacional, toxicologia ambiental, toxicologia de alimentos, toxicologia de medicamentos, toxicologia social, etc. Neste sentido, a toxicologia através de suas técnicas científicas vem somar esforços junto a perícia criminal e a própria saúde pública em seu sentido macro.

Palavras-chave: Perícia. Provas. Laudo. Saúde-pública. Toxicologia.

ABSTRACT: The purpose of this paper is to discuss the topic of forensic toxicology as an essential tool for the identification of substances harmful to organisms, since, often, the inappropriate use of certain chemical reagents, can cause irreparable damage; presenting itself, therefore, as a topic of high relevance to public health and society in general. In this sense, the expert's role is presented as a "sine qua non" to elucidate crimes and infractions in cases of poisoning; drug overdose; changes of substances, where through analysis and collection of biological material, such professional will raise concrete subsidies in order to obtain conclusive evidence, corroborated in his technical report. In this area of knowledge, professionals from different backgrounds work and, therefore, it is understood as multidisciplinary, for example: occupational toxicology, environmental toxicology, food toxicology, drug toxicology, social toxicology, etc. In this sense, toxicology, through its scientific techniques, joins efforts with criminal expertise and public health itself in its macro sense.

keywords: Expertise. Evidences. Public-health. Report. Toxicology.

\footnotetext{
${ }^{1}$ Mestranda em Direito da Saúde: Dimensões individuais e coletivas pela Universidade Santa Cecília

${ }^{2}$ Mestrando em Direito da Saúde: Dimensões individuais e coletivas pela Universidade Santa Cecília
} 


\section{INTRODUÇÃO}

A toxicologia é uma ciência que estuda os efeitos nocivos das substâncias químicas nos sistemas vivos. Considerando o conceito mais amplo de necropsia, a toxicologia deve ser entendida como uma fonte multidisciplinar, que engloba os conhecimentos da Farmacologia, da Bioquímica, da Química, da Fisiologia, da Genética, da Patologia, entre outros. Tem-se como objetivo estudar a interação entre os agentes químicos e o nosso sistema biológico, visando determinar o quão danoso pode ser tal reagente químico e quais os efeitos adversos verificados em diferentes organismos.

$\mathrm{Na}$ área forense, a ciência é aplicada com propósitos específicos, quase sempre dentro de infrações, contravenções e crimes, detectando e quantificando todas estas substâncias. As principais técnicas de análise toxicológica, no Brasil, variam desde métodos não instrumentais até os mais sofisticados, utilizando-se para a perícia, materiais biológicos como sangue, urina e cabelo. Nos dias atuais houve um grande aumento do interesse para com a área e toda essa movimentação se dá pelos muitos seriados que retratam a ciência forense. Destarte o objetivo deste estudo é compreender a atuação e importância da toxicologia forense e é nesse contexto que abordaremos os tópicos que seguem. Para tal, este trabalho subdivide-se em capítulos, que farão compreender o fito geral supracitado.

\section{CONCEITO}

A toxicologia é uma ciência que identifica os diversos efeitos associados com a exposição a determinados agentes tóxicos. Tal ciência, no âmbito forense, objetiva detectar e quantificar as substâncias potencialmente nocivas e aplicá-las em questões judiciais, visto a necessidade do reconhecimento, da identificação e da quantificação do risco relativo à exposição humana a agentes tóxicos (RANGEL, 20II).

Assim, a toxicologia forense serve para detectar e quantificar as substâncias tóxicas que podem ser encontradas em situações criminais. Ocorre que estes tipos de substâncias são demasiadamente comuns de serem encontradas e acabam por limitar a realização das perícias, pois sobrecarregam os laboratórios que, por sua vez, direcionam sua busca apenas para estes elementos (ALVES, 2005). 
Para Rozenfeld (1998), não existe substância química totalmente segura ou totalmente tóxica, a estimativa do risco requer a compreensão dos mecanismos de processamento dos efeitos tóxicos que embasam as classificações. Neste sentido, Paracelsus (I493-I54I), em meados do século XIV, revolucionou a história da medicina, passando a ser considerado como o Pai da Toxicologia e nos deixou como legado sua frase marcante, muito utilizada nos dias de hoje: "a dose correta é o que diferencia o veneno de um remédio". Dessa forma, por mais inofensiva que pareça ser alguma substância, se usada de forma indiscriminada, pode se tornar letal.

Um agente químico pode produzir efeitos agudos, subletais, letais ou crônicos sobre um organismo. Quando tratamos do efeito tóxico não devemos levar em consideração tão somente a substância em si, mas também a concentração deste agente tóxico no organismo afetado (GOES, 1998).

A intoxicação é uma forma de envenenamento e é caracterizada como uma manifestação clínica do efeito nocivo produzido em um organismo vivo; é o resultado da interação entre um agente tóxico e um corpo suscetível. O grau da toxicidade e suas manifestações dependerão não só da substância, como também da dose ou concentração, das propriedades desta matéria, da via, tempo e frequência de exposição e suscetibilidade do organismo. (CHASIN, PEDROZO, \& CHASIN, 2004; LARINI, 1997).

Em sua maioria, a intoxicação se dá em pessoas sadias que somente desenvolvem algum sinal e sintoma após o contato com algum tipo de matéria externa. A matéria causadora pode vir do uso industrial, humano, médico, doméstico, agrícola, automotivo, dentre outros; o resultado fático é o efeito tóxicos causado pela exposição e uso inapropriado ou exagerado da substância (OLIVEIRA \& MENEZES, 2003).

Segundo Tocchetto e Passagli (201I) a Toxicologia objetiva prevenir, diagnosticar e tratar o homem que eventualmente teve algum contato com substâncias químicas potencialmente venenosas, tóxicas ou xenobióticas. A toxicologia forense estuda as substâncias químicas geralmente na fase post mortem, ou seja, busca evidências no cadáver que permita a identificação da causa mortis por um agente tóxico; para que possa auxiliar a investigação criminal na elucidação em casos de acidentes, suicídios e homicídios.

Atualmente estes estudos acerca da toxicologia forense são cada vez mais amplos e indispensáveis, abrangendo desde perícias em seres pós mortem como em vivos, visando 
rastrear e/ou confirmar possível presença de drogas ilícitas para atestar um eventual estado de dependência psíquica e/ou física daquele indivíduo. Em casos mais extremos, auxiliam em circunstâncias da própria saúde pública, como falsificação ou adulteração de medicamentos e acidentes com substâncias químicas (TOCCHETTO \& PASSAGLI, 20II).

São dois os fatores para o risco potencial de substância química: a exposição e a toxicidade. Para a obtenção do conhecimento acerca dos efeitos destes elementos na saúde humana, são feitos exames a partir de duas fontes: estudos em seres humanos e estudos de toxicidade com animais (WHO, 2006) (GARCIA \& ALVES FILHO, 2005).

\section{A PERÍCIA COMO MEIO DE PROVA}

Como vimos, a toxicologia forense está intimamente ligada com os cabedais teóricos advindos da Medicina Legal, que por sua vez mantém estreito relacionamento com o Direito. Hélio Gomes (2004) afirma:

Sendo o Direito uma ciência humana, é preciso, em primeiro lugar, que o profissional do Direito tenha bom conhecimento do que é o ser humano em sua totalidade. [...] Para isto, não é necessário que possua o saber de um profissional da área biomédica, mas tem que conhecer as bases daquela unidade (GOMES, 2004, p. 26).

Se faz mister que os profissionais da perícia dominem os conhecimentos alusivos à ciência que os influenciam e neles se reproduzem. Para que ocorra a compreensão das normas e da boa gestão de sua aplicabilidade, deve o jurista angariar o arcabouço necessário acerca da matéria em pauta, já que a perícia, constituída como meio legítimo e indispensável de prova, abrange tanto a área penal, como também a cível e a trabalhista.

Os exames realizados pela perícia, sempre de forma técnica e minuciosa, requerem conhecimentos específicos, científicos e/ou artísticos. São solicitados por determinação de autoridade policial ou judiciária, onde estes podem determinar todo e qualquer tipo de perícia, tanto em pessoas como em objetos, conforme se faça necessário (ESTEFAM, 2008).

De acordo com o artigo I59 do CPP (BRASIL, 2005) temos: 
O exame de corpo de delito e outras perícias serão realizados por perito oficial, portador de diploma de curso superior.

§ 1o $\mathrm{Na}$ falta de perito oficial, o exame será realizado por 2 (duas) pessoas idôneas, portadoras de diploma de curso superior preferencialmente na área específica, dentre as que tiverem habilitação técnica relacionada com a natureza do exame.

§ 2을 Os peritos não oficiais prestarão o compromisso de bem e fielmente desempenhar o encargo.

§ $3^{\circ}$ Serão facultadas ao Ministério Público, ao assistente de acusação, ao ofendido, ao querelante e ao acusado a formulação de quesitos e indicação de assistente técnico.

§ $4^{\mathcal{O}}$ O assistente técnico atuará a partir de sua admissão pelo juiz e após a conclusão dos exames e elaboração do laudo pelos peritos oficiais, sendo as partes intimadas desta decisão .

O termo "perícia", proveniente do latim peritia, configura-se como conhecimento adquirido pela experiência, uma habilidade, maestria, trata-se "de um juízo de valoração científico, artístico, contábil, avaliatório ou técnico, exercido por especialista". Todo e qualquer fato ou vestígio considerado importante para o processo investigativo serão desígnio de perícia, não se admitindo, como objeto de prova, aquilo que for desútil para a ação (CAPEZ, 2005).

Neste sentido, perícia detém o propósito de obter informações contundentes a fim de clarificar dubiedade sobre fatos, através de exames realizados em indivíduos, coisas e animais, onde o profissional faz uso de todo seu arsenal de conhecimentos técnicocientíficos. Pelo fato de incidirem sobre fontes passivas (sobre o objeto em si), classifica-se como prova real, não estando sujeito, portanto, à variação de informações (DINAMARCO, 2008).

Embora não exista hierarquia entre as provas, Capez defende que a perícia técnica representa "um plus em relação à prova e um minus em relação à sentença", identificando-a como meio probatório de valor especial de natureza jurídica (CAPEZ, 2005)

A verificação de circunstâncias, de vestígios e fatos, através de exame, avaliação ou vistoria, traduz-se em constatação reconhecida juridicamente, onde, através de documento oficial, a perícia se vê incluída; na qual o laudo pericial deve ser balizado como prova crítica de descomunal valor (TOURINHO FILHO, 2008). Os laudos, devem apontar somente questões de ordem técnica, baseadas em normas jurídicas e científicas de acordo com a especificidade da área, não podendo admitir a formação de juízo de valor ou 
quaisquer suposições sem que haja suficientes indícios fáticos. Seu teor deve apresentar-se de forma esclarecedora, para que sirva, assim, de sustentação à decisão do juiz.

Toda vez que a infração deixar vestígios, será indispensável o exame de corpo de delito, como preconiza o artigo 158 do CPP. Esta análise pode ser direta, quando os peritos realizarem diretamente sobre a pessoa ou objeto, ou indireta, quando os peritos se basearem somente pelos depoimentos das testemunhas, no caso dos vestígios terem desaparecido. O exame de corpo de delito poderá ser realizado em qualquer dia ou hora, conforme artigo I6I do CPP, não sendo possível ocorrer, por terem desaparecido os sinais, a prova testemunhal bastará (artigo I67 do CPP) (BRASIL, 2005).

\section{Perícia Médico-legal E Sua Conexão Com A Toxicologia Legal E Sua Conexão Com A Toxicologia}

A perícia médico-legal colabora na apuração de todos os fatos de relevância ao âmbito jurídico, aditando toda a sapiência amealhada pelas ciências médicas. Desse modo, França (2008) a define como:

[...] Um conjunto de procedimentos médicos e técnicos que tem como finalidade o esclarecimento de um fato de interesse da Justiça. Ou como um ato pelo qual a autoridade procura conhecer, por meios técnicos e científicos, a existência ou não de certos acontecimentos, capazes de interferir na decisão de uma questão judiciária ligada à vida ou à saúde do homem ou o que com ele tenha relação (FRANÇA, 2008)

Todo procedimento médico, tais como exumação, necroscopia, exames laboratoriais e clínico, determinado por autoridade policial ou judicial, no que tange a perícia médicolegal, é exercido pelo profissional de Medicina e objetiva coadjuvar a justiça (GOMES, 2004).

Após todo o deliberado, vislumbra-se o alto grau de importância tanto da ciência Médica para o Direito, quanto da perícia de modo geral, para o embasamento fático jurídico. Percebe-se, em conformidade com o exposto, que a perícia médico-legal é inerente à toxicologia forense e perícia criminal, visto ser um meio de prova peculiar, através da qual aplica-se conhecimentos técnicos da Medicina para dirimir questões que se mantém inexplicáveis acerca de um corpo sadio que apresentou toxicidade ainda em vida, ou em casos mais graves, em uma possível morte. É de interesse da Justiça esta relação multidisciplinar, visto a necessidade de o julgador conseguir, mediante laudos periciais, dirimir as questões sem o auxílio do conhecimento especializado. 
As perícias médico-legais não se referem apenas a exames executados no post mortem. Temos em nosso presente um grande aumento de indivíduos que sofrem com a dependência alcoólica. Além do álcool, que é o mais usual, a medicina-legal ainda pode encontrar substâncias psicotrópicas e estupefacientes, intoxicações por pesticidas, fármacos, gases, metais pesados, xenobióticos corrosivos e por solventes orgânicos.

Cabe a área toxicológica executar perícias investigativas em humanos, que implicam na constatação de substâncias tóxicas tanto em organismo vivo, quanto em cadáver. São levados em consideração procedimentos que garantam a qualidade da cadeia de custódia, sempre objetivando o esclarecimento de questões envolvidas no âmbito judicial.

Dentro das amostras mais amplamente analisadas pela medicina-legal na constatação de toxicidade estão: órgãos colhidos na autópsia, fluídos biológicos obtidos do cadáver ou do vivo, e produtos orgânicos e inorgânicos suspeitos (líquidos, sólidos, vegetais, etc.)

Ato contínuo, efetua-se a seleção e colheita das amostras mais adequadas. Importante ressalvar que, as amostras recolhidas devem ser tratadas com muito cuidado, não se pode adicionar qualquer preservante ou conservante; seu acondicionamento deve-se atender às condições de luz, umidade e calor (fontes prováveis de reações de oxidação ou hidrólise que podem acelerar a decomposição dos produtos), a remessa deve obedecer a critérios rigorosos para que nada invalide a prova; estes e outros cuidados são passos fundamentais à preservação e correta realização da perícia (RANGEL, 2003/2004).

Quando se trata de pessoas ainda vivas, os exames toxicológicos têm o objetivo de rastrear e confirmar uma eventual presença de drogas caracterizadoras como toxicodependência para que se possa avaliar o grau da intoxicação e se isto pode vir a ser uma circunstância qualificadora de delito ou de inimputabilidade. Desta feita, a Polícia Técnico-Científica tem a função de garantir a cadeia de custódia, não só de produtos e amostras, como também dos exames de quantificação de álcool etílico no sangue e urina. (ALVES, 2005).

A morte por intoxicação se encaixa no âmbito da morte violenta, neste caso, deve ser efetuada à autópsia médico-legal e, consequentemente, à requisição de perícia toxicológica (BRASIL, 194I). Visto todo o exposto, conclui-se pela impossibilidade de 
tratar a toxicologia forense sem que tenhamos conhecimentos alicerçados no tocante à medicina-legal e perícia criminal.

\section{LAUDO TOXICOLÓGICO}

Visto que determinados crimes, deixam vestígios materiais (facta permanentes), se faz necessário colocar a termo os componentes e circunstâncias do fato para que se comprove a materialidade do delito.

O laudo, apresenta-se em forma de relatório, devendo conter tanto a interpretação dos resultados encontrados e ainda os seguintes dados: identificação do processo ou inquérito e da entidade requisitante; método analítico utilizado e referências à técnica de isolamento utilizada; datas de recepção de amostras e de conclusão dos exames; amostras analisadas; especialista responsável pela execução das análises; níveis de detecção e de quantificação; estado das amostras analisadas, e outros que possam ser considerados relevantes para elaboração de conclusões. O Laudo de Perícia Toxicológico é expedido ao profissional que solicitou a perícia (Perito Legista), sendo a posteriori, encaminhado em separado ou em conjunto com o Laudo de Autópsia ou de Clínica Médico-Legal, à instituição pleiteante (ALVES, 2005).As intoxicações podem ser classificadas em: criminais; legais (pena de morte); acidentais (alimentares, mordedura de animais, absorção acidental, medicamentosas) ou voluntárias (lesões auto infligidas, toxicodependência e terapêutica). Quando levamos em consideração a velocidade do desencadeamento de ações ou dos efeitos tóxicos, encontramos 3 formas de intoxicação: aguda, subaguda e crônica. As substâncias tóxicas têm o potencial de agir nas células de forma destrutiva através de processos de necrose, sobre o sistema enzimático ou, ainda, sobre partes seletivas da célula (ALVES, 2005). Para que a análise dos dados seja melhor interpretada, e para que o laudo técnico seja bem embasado, podendo, ser fruído como documento de prova jurídicocriminal, deve-se levar em conta alguns fatores: dose; via de administração; efeitos aditivos; antagonismo ou sinergismo (devido a associação com outras substâncias); estados patológicos existentes; idiossincrasias. 


\section{Substâncias Químicas X Saúde:}

Muitos fatores implicam na qualificação (boa ou ruim) de agentes químicos à saúde, já que tanto o estilo de vida quanto os aspectos sociais e econômicos, podem interferir nesse sentido. A intoxicação, geralmente, esculpe-se de forma rápida e implacável, apresentando resultados intensos e violentos. A exposição do indivíduo às substâncias tóxicas por grande período de tempo, ocasiona efeitos crônicos, tornando-se difícil sua identificação pela exposição a elas, já que, atualmente, o homem está sujeito a uma gama imensa de substâncias químicas nos alimentos, no ar, na água, nos medicamentos(KLAASSEN, et al., 1996).

A complexidade sócio-ambiental no Brasil em consonância com a vulnerabilidade populacional / institucional; meios de produção obsoletos; ou em sua contramão, a adesão de tecnologias altamente avançadas, vem alterando, significativamente, a forma de inserção social, ocasionando, de forma indiscriminada, a ingerência de recursos naturais e consequentemente, a contaminação/degradação/ poluição química do meio. De maneira reflexa houve, em nosso país, um crescimento exorbitante no que tange aos problemas relacionados à segurança química, no entanto, não ocorreu o mesmo com relação ao seu enfrentamento, infelizmente (FREITAS et al. 2002).

Visando fortalecer e qualificar a Assistência Farmacêutica nos estados e municípios, a Agência Nacional de Vigilância Sanitária (ANVISA), devido sua amplitude do campo da atuação sanitária, optou pela reestruturação, anuindo a responsabilidade institucional pelas atividades de Farmacovigilância. Desta feita, foi necessária inclusive a institucionalização da UFARM, com o intento de implementar a Política Nacional de Medicamentos (PNM), aliada a outras táticas.

Laport e Tognoni (1993), propõe a Toxicovigilância no sentido de identificar e avaliar o risco, dos efeitos crônicos e agudos, de substâncias químicas utilizadas de diversas maneiras pela sociedade, incluindo grupos específicos. Nesta mesma via, frisa-se a importância de investigar (através de um conjunto de medidas e ações), como ocorrem as intoxicações e quais fatores estão relacionados. (LAPORTE \& TOGNONI, 1993).

Interligado ao Ministério da Saúde, consta o Sistema Nacional de Informações Tóxico-Farmacológicas (Sinitox) que conta com a precípua atribuição de coordenar a 
coleta, a compilação, a análise e a divulgação dos casos de intoxicação e envenenamento notificados no país. Tais registros são efetuados pelos Centros de Informação e Assistência Toxicológica (Ciats), localizados em vários estados brasileiros, onde parte deles integram a Rede Nacional de Centros de Informação e Assistência Toxicológica (Renaciat). As notificações são encaminhadas ao Sinitox, já que este é o órgão responsável pela consolidação e divulgação anual dos dados, em âmbito nacional.

O Sistema também desenvolve atividades de pesquisa nas áreas de intoxicação, informação em saúde e saúde pública, contribuindo para o enriquecimento destas discussões no cenário brasileiro de intoxicação e envenenamento, principalmente no que concerne a questões preventivas.

A atualização de dados discernentes quanto às condições de saúde populacional, no tocante ao conjunto de indicadores básicos, decorrem de estudos e análises de informações, devendo ocorrer de forma periódica, para que o aprimoramento do sistema aconteça de maneira progressiva. No entanto, a precisão destas informações, irão depender da qualidade dos dados, já que estes estão expostos a interferência de múltiplos fatores (técnicos, operacionais, entre outros). A consistência das análises realizadas é de grande monta em relação à Vigilância Epidemiológica, visto que nada se faz sem a obtenção de informações.

Em contrapartida, para que o sistema de informações seja eficiente (enquanto processo) e eficaz (quanto ao resultado) é de capital importância, além do abastecimento periódico de dados / informações relevantes, o preenchimento criterioso de instrumentos de coleta de dados, tais como: fichas de notificação e investigação; boletins de atendimento; declaração de óbito; declaração de nascido vivo; relatórios; autorizações de internação etc. Salienta-se que a conversão de dados (valor quantitativo) em informação (análise crítica descritiva de dados) pode ser feita em todos os níveis do sistema de saúde. (HENNEKENS, 1987).

\section{Substâncias Tóxicas Sujeitas A Controle No Brasil}

Em nosso país, a ANVISA detém a responsabilidade de publicar a lista de substâncias e medicamentos sujeitos a controle especial. 
Em 1998 estabeleceu-se uma relação de substâncias controladas, gerando assim uma Portaria. Desta feita, as substâncias sujeitas a controle especial estão descritas na Portaria 344/98, onde o órgão atualiza periodicamente o anexo, com as devidas inclusões/alterações da lista. (BRASIL, I998).

Dentre as diversas classificações, temos as chamadas substâncias controladas ou sujeitas a controle especial, por se tratar de substâncias que agem no sistema nervoso central, capazes de causar dependência física ou psíquica, requerem controle mais rigoroso do que o exigido para as substâncias comuns.

São classificados como medicamentos controlados, segundo a Portaria SVS / MS no 344/1998: substâncias anabolizantes; substâncias abortivas ou que causam má-formação fetal; substâncias que podem originar psicotrópicos; insumos utilizados na fabricação de entorpecentes e psicotrópicos; plantas utilizadas na fabricação de entorpecentes; substâncias químicas de uso das forças armadas e as substâncias de uso proibido no Brasil (BRASIL, 1998).

Lista de substâncias de medicamentos sujeitos a controle especial no Brasil, temos a seguinte classificação:

- Lista AI - Substâncias entorpecentes

- Lista $\mathrm{A}_{2}$ - Substâncias entorpecentes de uso permitido somente em concentrações especiais

- Lista $\mathrm{A}_{3}$ - Substâncias psicotrópicas

- Lista $\mathrm{B}_{\mathrm{I}}$ - Substâncias psicotrópicas.

- Lista $\mathrm{B}_{2}$ - Substâncias psicotrópicas anorexígenas

- Lista $\mathrm{C}_{\mathrm{I}}$ - Outras substâncias sujeitas a controle especial.

- Lista $\mathrm{C}_{2}$ - Substâncias retinóicas

- Lista $\mathrm{C}_{3}$ - Substâncias imunossupressoras

- Lista $\mathrm{C}_{4}$ - Substâncias anti-retrovirais

- Lista $\mathrm{C}_{5}$ - Substâncias anabolizantes

- Lista Di - Substâncias precursoras de entorpecentes e/ou psicotrópicos

- Lista $\mathrm{D}_{2}$ - Insumos químicos utilizados para fabricação e síntese de entorpecentes e/ou psicotrópicos.

- Lista E - Plantas proscritas que podem originar substâncias entorpecentes e/ou psicotrópicas

- Lista FI - Substâncias entorpecentes

- Lista $F_{2}$ - Substâncias psicotrópicas 
- Lista $\mathrm{F}_{3}$ - Substâncias precursoras

- Lista $\mathrm{F}_{4}$ - Outras substâncias

\section{CONSIDERAÇÕES FINAIS}

A toxicologia como ciência e sua relevância com a perícia criminal, visa detectar e qualificar as substâncias tóxicas que podem ser encontradas no âmbito penal. É, de fato, uma ciência que estuda os efeitos nocivos provocados por diversas substâncias em contato com os organismos vivos.

Nesta área de conhecimento, atuam profissionais de diversas formações e por isso é entendida como uma área multidisciplinar, por exemplo: toxicologia ocupacional, toxicologia ambiental, toxicologia de alimentos, toxicologia de medicamentos, toxicologia social, etc..

A toxicologia através de suas técnicas científicas vem somar esforços junto a perícia criminal, para desvendar qual reagente químico fora utilizado dentro daquela constatação de crime. Fora da área penal, a grande finalidade da toxicologia é prevenir, diagnosticar e tratar as intoxicações.

Podemos, com o avançado estudo deste tema, verificar as possibilidades de investigação de mortes causadas por intoxicação, desembocando em três etapas: obtenção do histórico do caso e a busca pelo máximo de informação acerca da cena do crime, realização das análises toxicológicas nas amostras coletadas e a interpretação de tudo aquilo que foi encontrado.

Resta-se demonstrado a importância da perícia toxicológica na área jurídica, sem esta não haveria um meio eficaz de atingir um propósito. Quanto mais bem executado o corpo de delito, quanto mais resíduos e informações coletados, maior será a chance de o perito atingir seu verdadeiro fito e elaborar um Laudo completo e eficaz, ou seja, quanto mais técnico, específico e científico for o seu laudo, melhor obtenção de resultados, prestando assim, serviço de extrema relevância à saúde pública e a sociedade em geral.

\section{REFERÊNCIAS BIBLIOGRÁFICAS}

ALVES, S. R. Toxicologia Forense e Saúde Pública: Desenvolvimento e Avaliação de um Sistema de Informações como ferramenta para a vigilância de agravos decorrentes da utilização de substâncias químicas. Tese (Doutorado - Departamento de Centro de Estudos da Saúde do Trabalhador e Ecologia Humana). Escola Nacional de Saúde 
Pública/Fundação Oswaldo Cruz, Rio de Janeiro, 2005. Disponível em: $\langle$ http://www.fiocruz.br/sinitox_novo/media/artigo7.pdf $\rangle$. Acesso em: 22 de maio de 2021.

BRAGA, A. Estrutura dos modelos de laudo pericial (rotina prática). 2013. Disponível em: $<$ http://periciacriminalalagoana.blogspot.com.br/2013/o2/estrutura-dos-modelos-delaudo-pericial.html $>$ Acesso em: is de agosto de 2020.

BRASIL. Agência Nacional de Vigilância Sanitária. Portaria no 344, de 12 de maio de 1998. Aprova o Regulamento Técnico sobre substâncias e medicamentos sujeitos a controle especial. [S. 1.], 3I maio 202I. Disponível em: https://bvsms.saude.gov.br/bvs/saudelegis/svs/1998/prt0344_12_05_1998_rep.html. Acesso em: 3I maio 202I.

BRASIL. Decreto-Lei no 2.848 , de 7 de dezembro de 1940. Da aplicação da lei penal. Diário Oficial da União: Brasília, DF, I940.

BRASIL. Decreto-Lei no 3.689, de 3 de outubro de 1941. Código do Processo Penal. Diário Oficial da União: Brasília, DF, 194I.

BRASIL. Secretaria Nacional de Segurança Pública. Procedimento operacional padrão: perícia criminal. Ministério da Justiça, Brasília, 2013.

CAPEZ, F. Curso de processo penal. i2. ed. rev. e atual., São Paulo: Saraiva. 2005.

CHASIN, A. A., PEDROZO, M. F., \& CHASIN, A. A. Estudo da Toxicologia.As bases toxicológicas da ecotoxicologia. São Paulo: RiMa, 2004.

DINAMARCO, C. R. Instituições de Direito Processual Civil. São Paulo: Malheiros, 2008.

ESPINDULA, A. Laudo Pericial e outros documentos técnicos. 2008. Disponível em: 〈http://www.conteudojuridico.com.br/artigo,laudo-pericial-e-outros-documentostecnicos,22509.html>. Acesso em: 22 de jan. de 202r.

ESTEFAM, A. Provas e procedimentos no processo penal. Damásio de Jesus, São Paulo. 2008. 
FERNANDES, É. T. Importância da perícia no local do crime na investigação criminal. 2014. Acesso em: 22 de agosto de 2020, Disponível em: https://erikatamires.jusbrasil.com.br/artigos/153307203/importancia-da-pericia-no-localdo-crime-na-investigacao-criminal

FRANÇA, G. V.. Medicina Legal. 8. ed., Rio de Janeiro: Guanabara Koogan, 2008.

GARCIA, E. G., \& ALVES FILHO, J. P. Aspectos de prevenção e controle de acidentes no trabalho com agrotóxicos. São Paulo: Fundacentro, 2005.

GOES, R. C. Toxicologia Industrial. Rio de Janeiro: Livraria e Editora Revinter Ltda, 1998.

GOMES, H. Medicina Legal - Atualizador Hygino Hercules. 33. ed. rev. e atual., Rio de Janeiro: Freitas Bastos, 2004.

LAPORTE, J., \& TOGNONI, G. Estudios de utilización de medicamentos y farmacovigilancia. In: LAPORTE, J.R.; TOGNONI, G. Principios de epidemiología del medicamento. 2.ed. Barcelona, Masson - Salvat, 1993.

LARINI, L. Avaliação Toxicológica. In: Toxicologia. São Paulo: Manole, 1997.

OLIVEIRA, R. D., \& MENEZES, J. B. Intoxicações exógenas em clínica médica. Simpósio: Urgências e emergências dermatológicas e toxicológicas, Ribeirão Preto, 2003.

RANGEL, R. Medicina Legal/Noções gerais sobre outras ciências forenses: Toxicologia Forense, Faculdade de Medicina da Universidade do Porto, 2003/2004.- I CD-ROM. Disponível em: 〈http://medicina.med.up.pt/legal/NocoesGeraisCF.pdf〉. Acesso em: I2 de maio de 2021.

RANGEL, R. Noções Gerais Sobre Outras Ciências Forenses. Disponível em Faculdade de Medicina da Universidade do Porto: $\langle\underline{\text { http:}} / / /$ medicina.med.up.pt/legal/NocoesGeraisCF.pdf $\rangle$ Acesso em: 20 de ago. de 2020. 
REI, F. Toxicologia Forense. Disponível em Toxicologia UFSJ: http://toxicologiaufsj.blogspot.com.br/2011/II/toxicologia-forense-toxicologiaforense.html Acesso em: 02 de fev. de 2021.

TOCCHETTO, D., \& PASSAGLI, M. Tratado de Perícias Criminalísticas:Toxicologia Forense - Teoria e Prática. Campinas: 3. ed Millennium, 201 .

TOURINHO FILHO, F.. Processo Penal. 3o. ed. rev. e atual., São Paulo: Saraiva, 2008.

WHO - World Health Organization. Guidelines for drinking - water quality. Disponível em: Third Edition. I $^{\text {a }}$ Addendum to vol. I. Geneva. Disponível em: $\langle$ http://www.who.int/water_sanitation_health/dwg/gdwqo506.pdf $>$ Acesso em: 23 de maio de 2021. 